\title{
Carbene Spin Multiplicity in Solution Probed Using Time-Resolved EPR Spectroscopy
}

\author{
Jin Wang, ${ }^{1}$ Natalia V. Lebedeva,${ }^{2}$ Matthew S. Platz, ${ }^{1}$ and Malcolm D. E. Forbes ${ }^{2,}$ \\ ${ }^{1}$ Department of Chemistry, The Ohio State University, 100 W. 18th Avenue, Columbus, OH 43210 \\ 2 Department of Chemistry, Caudill Laboratories, The University of North Carolina, Chapel Hill, NC 27599, *mdef@unc.edu
}

Dedicated to the memory of Ernest L. Eliel, a scholar and a gentleman in the truest sense

Received July 24, 2009; accepted September 21, 2009

\begin{abstract}
Time-resolved (CW) EPR spectroscopy at X-band has been used to detect free radicals created by $\mathrm{H}$-atom abstraction reactions of photochemically generated carbenes in $n$-hexadecane solutions at room temperature. Three different carbenes were studied, formed via loss of nitrogen after photo-excitation of a substituted biphenyl diazo precursor. The TREPR signals from two different alkyl radicals and the benzylic-type radical from the carbene are detected for two of the three diazo substrates. The radicals were unambiguously identified by spectral simulation using literature parameters ( $g$-factors and hyperfine coupling constants). Previous transient optical absorption spectroscopy experiments have concluded that these two carbenes have triplet ground states, which is confirmed by the low field emissive, high field absorptive phase of the TREPR signals reported here. The spectra are strongly spin polarized by the Radical Pair Mechanism of CIDEP, and their overall intensities track with the measured quantum yields for carbene production. A third substrate, known to react via a concerted Wolff reaction or excited state rearrangement via a singlet state, showed no TREPR signal, as expected. Reactions run in acetonitrile, where the spin multiplicity is reversed to give a singlet ground state, did not lead to detectable TREPR signals for all three substrates. The observations are consistent with previously published laser flash photolysis results.
\end{abstract}

Keywords: Time-resolved EPR Spectroscopy, Free Radicals, Carbene Spin Multiplicity, Laser Flash Photolysis.

\section{Introduction}

Carbenes are important reactive intermediates and have been extensively studied since the 1950 s by a wide variety of physical methods and ever improving theory [1]. They are understood to have two possible spin states, singlet and triplet, which can interconvert if there is a small energy gap between them. Due to their different electronic configurations, triplet and singlet carbenes exhibit very different chemical reactivity patterns. Singlet carbenes behave like zwitterions, while triplet carbenes undergo chemical reactions more typical of free radicals. Thus, to understand carbene reactivity it is important to determine the carbene ground state multiplicity and the energy gap between the singlet and triplet. A large volume of product analyses for carbene reactions has provided a sturdy framework with which to study the ground state multiplicity [2]. Modern experimental spectroscopies in low temperature
Resumen. Espectroscopía de resonancia paramagnética electrónica (EPR por las siglas en inglés) fue utilizada para detectar los radicales libres formados mediante reacciones de abstracción de átomos de hidrógeno de diversos carbenos generados fotoquímicamente en soluciones de $n$-hexano y a temperatura ambiente. En particular, se describe el análisis de tres carbenos que fueron generados por fotoexcitación de un bifenilo con dos grupos diazo. Se identificaron señales EPR de dos radicales alquilo y uno bencílico. La estructura de dichos radicales se confirmó mediante un proceso de simulación computacional utilizando parámetros espectroscópicos (factores- $g$, constantes de acoplamiento hiperfino) reportados en la literatura. Experimentos previos de absorción óptica han llevado a la conclusión de que los carbenos estudiados presentan un estado basal de tipo triplete, lo que se confirma al observar las señales EPR de emisión a campo bajo pero de absorción a campo alto. Además, se encontró que los espectros presentan un espín fuertemente polarizado como consecuencia de un mecanismo CIDEP, y que la intensidad de las señales está relacionada con los rendimientos cuánticos asociados a la producción de los carbenos iniciales. Como era de esperarse, un tercer sustrato, que reacciona vía una reacción concertada de tipo Wolff a través de un reordenamiento del intermediario singulete producido en el estado excitado, no dio lugar a ninguna señal EPR. Así mismo, cuando las reacciones de los tres carbenos se llevan a cabo en acetonitrilo, la multiplicidad del espín se invierte de modo que se genera un estado basal.singulete, por lo que no se observan señales EPR. Los resultados descritos en este trabajo son consistentes con aquellos obtenidos mediante fotólisis láser.

Palabras clave: Espectroscopía de resonancia paramagnética electrónica, radicales libres, multiplicidad de espín, carbenos, fotólisis láser.

matrices, such as UV, IR and EPR, have also been used to great advantage [3]. Time-resolved methods such as laser flash photolysis with nanosecond and even sub-picosecond time resolutions, have provided reactive intermediate lifetimes [4], and magnetic resonance methods such as CIDNP have provided high resolution structural information [5]. Additionally, modern computational chemistry has made a significant contribution to our understanding of carbene structure and reactivity [6]. Indeed, the convergence of theory and experiment in regard to the singlet-triplet energy gap of the simplest carbene, methylene, can be regarded as one of the crowning achievements of physical organic chemistry in the 20th century $[7,8]$.

Carbene-solvent interactions have long been appreciated to affect carbene reactivities. A seminal study in the 1980's by Eisenthal and coworkers correlated the carbene singlettriplet intersystem crossing rate, and indirectly the energy gap between them,with the solvent polarity parameter $\mathrm{E}_{\mathrm{T}}(30)$ 
[9]. It was proposed that the singlet carbene ground state is differentially favored in polar solvents due to its zwitterionic character. When the triplet carbene is the ground state, polar solvents can decrease the singlet-triplet carbene energy gap. This so-called "Eisenthal's rule" has been widely accepted by the carbene chemistry community since that time [10]; e.g., Toscano and co-workers have directly demonstrated the link between solvent polarity and ground state multiplicity using ns time-resolved IR spectroscopy and theory [10a-b].

One of our laboratories (MSP) has recently used ultrafast laser flash photolysis techniques to study carbene chemistry and reported some exceptions to Eisenthal's rule. It was found that non-polar halogenated solvents, which were not used in Eisenthal's experiments, can retard ISC rates and the rates of other intramolecular processes (presumably by stabilizing singlet carbenes by coordination) just as effectively as polar solvents [11]. It has also been deduced that coordinating solvents can invert the ground state multiplicity of a carbene as reported previously [11-13]. There is therefore a great need to understand carbene ground state multiplicity in different solvents.

Aryltrifluoromethylcarbenes have long been thought to have triplet ground states. A recent study by Wang and Platz pointed out the solvent dependent ground state multiplicity of $p$-biphenylyltrifluoromethylcarbene $\left(\mathrm{BpCCF}_{3}\right)$ based on experimental and computational studies [12]. In that work, a diazo precursor was used to photolytically generate $\mathrm{BpCCF}_{3}$ (Scheme 1A). The singlet state of $\mathrm{BpCCF}_{3}$ is initially formed.

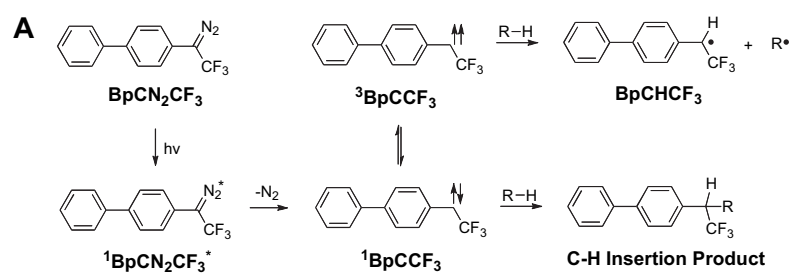

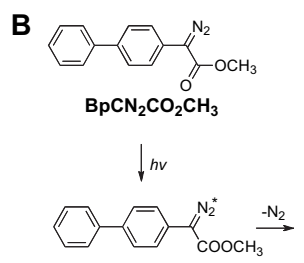

${ }^{1} \mathrm{BpCN}_{2} \mathrm{CO}_{2} \mathrm{CH}_{3}{ }^{*}$
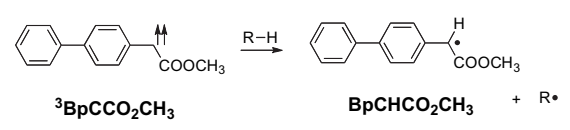

1

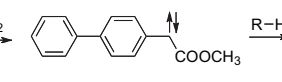

${ }^{1} \mathrm{BpCCO}_{2} \mathrm{CH}_{3}$

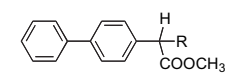

C-H Insertion Product

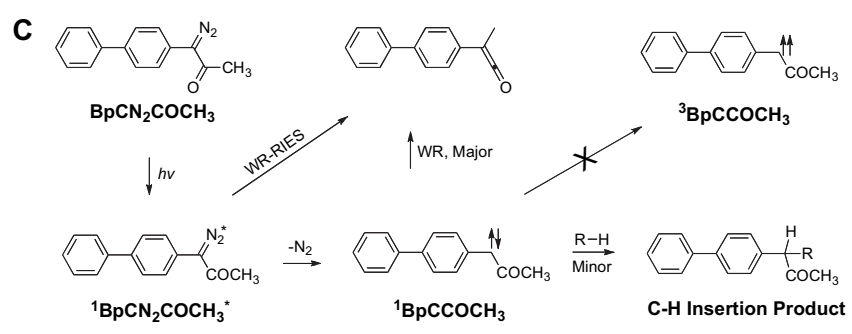

WR = Wolff Rearrangement; RIES = Rearrangement in the Excited State
In non-polar alkane solvents, ${ }^{1} \mathrm{BpCCF}_{3}$ undergoes direct $\mathrm{C}-\mathrm{H}$ insertion with the solvent to produce a carbene adduct. Also, ${ }^{1} \mathrm{BpCCF}_{3}$ can relax via intersystem crossing to form ${ }^{3} \mathrm{BpCCF}_{3}$, which subsequently abstracts a hydrogen atom to form the corresponding radical pair. In acetonitrile or halogenated solvents it was concluded that $\mathrm{BpCCF}_{3}$ has a singlet ground state due to solvent polarity and coordination effects. Recently, Wang and Sheridan reported that 2-benzothienyl(trifluoromethyl)-carbene has a singlet ground state in low temperature matrices [14].

To assess the structural parameters affecting this solvent dependence, a series of other arylcarbenes was also studied by Wang and Platz using ultrafast flash photolysis. They found that similar to $\mathrm{BpCCF}_{3}$, a biphenyl ester carbene $\left(\mathrm{BpCCO}_{2} \mathrm{CH}_{3}\right)$ has a triplet ground state in cyclohexane but a singlet ground state in acetonitrile and in dichloromethane [13]. In non-polar alkane solvents, as is the case with ${ }^{1} \mathrm{BpCCF}_{3},{ }^{1} \mathrm{BpCCO}_{2} \mathrm{CH}_{3}$ undergoes intersystem crossing to form the lower energy triplet spin isomer in competition with direct $\mathrm{C}-\mathrm{H}$ insertion to form carbene adduct (Scheme 1B). The formed ${ }^{3} \mathrm{BpCCO}_{2} \mathrm{CH}_{3}$ will react with the alkane solvent to form a radical. It is interesting to note that there was no Wolff rearrangement observed either in the excited state of the diazo precursor or in ${ }^{1} \mathrm{BpCCO}_{2} \mathrm{CH}_{3}$.

To compare the above observations with the biphenyl ester carbene, a biphenylyl ketocarbene $\left(\mathrm{BpCCOCH}_{3}\right)$ was also studied $[13,15]$. As described in Scheme 1C, the chemistry of $\mathrm{BpCCOCH}_{3}$ and its diazo precursor is very different from that of $\mathrm{BpCCF}_{3}$ and $\mathrm{BpCCO}_{2} \mathrm{CH}_{3}$. Upon photolysis of the ketocarbene diazo precursor, the singlet excited state of the diazo compound was formed, which bifurcates to produce singlet $\mathrm{BpCCOCH}_{3}$ and undergo a Wolff-like rearrangement. The majority of the ${ }^{1} \mathrm{BpCCOCH}_{3}$ formed also undergoes the Wolff rearrangement. No ${ }^{3} \mathrm{BpCCOCH}_{3}$ was observed. It was concluded that $\mathrm{BpCCOCH}_{3}$ has a singlet ground state in all the solvents employed in that study.

Transient optical absorption and kinetic measurements are by far the most common physical methods used to study carbene reactivity, but it is important to supplement such data with other higher resolution spectroscopic information, particularly by magnetic resonance if possible. In fact, the technique of chemically induced nuclear spin polarization (CIDNP) was found to be of great utility in the study of carbene chemistry almost as soon as it was developed in the late 1960's and early 1970's [16]. In such experiments, the products of the carbene reaction are observed by NMR spectroscopy and the phase of their signals allows researchers to assign the spin multiplicity of the species that created them. Comparisons of thermal vs. photochemical reactions often allowed immediate assignment or confirmation of carbene ground states [17].

The CIDNP experiment, which measures nuclear spin polarization intensities, has been used quite frequently to study carbene reactivity. However, to the best of our knowledge, the electron spin analog, chemically induced electron spin polarization (CIDEP) [18] has never been reported as a tool to supplement carbene ground state information. The CIDEP signal phase also contains spin multiplicity information, but 
has the advantage of providing direct structural information about the reactive intermediates involved in the mechanism. Additionally, a qualitative estimate of the quantum yield for free radical production from photochemically generated carbene can also be obtained from CIDEP intensities. As part of our (MDEF) laboratories' continued interest in developing a "cradle-to-grave" understanding of free radical reactions, we present here a time-resolved EPR spectroscopic investigation of the reactions shown in Scheme 1. The results provide a strong supportive link between the ultrafast optical absorption data and product analyses reported previously. They also demonstrate the utility of the TREPR experiment and associated CIDEP patterns in establishing mechanism in organic photochemistry.

\section{Results and Discussion}

Triplet carbenes themselves are not directly observable in solution using EPR spectroscopy in either steady-state or timeresolved modes due to their fast internal electron spin relaxation rates, which is efficiently induced by the dipolar interaction between the unpaired electrons. For similar reasons, the excited triplet states of most small organic molecules are also not observed in liquid solution. Both molecular triplet states and triplet carbenes can be observed and characterized in frozen matrices (glasses or single crystals) by EPR spectroscopy, but information about reactivity is not readily available in such experiments. If a suitable solvent is used, triplet carbenes will undergo the $\mathrm{H}$-atom abstraction reaction in solution, as shown in the top right of Schemes 1A and 1B. This reaction produces a radical pair consisting of a benzylic-type radical from the carbene, and an alkyl radical from the solvent. If the reaction is run in a TREPR spectrometer, the resulting transitions should be spin polarized by the Radical Pair Mechanism (RPM) [18] of CIDEP, and the phase of this polarization should reflect the ground state spin multiplicity of the carbene. A triplet state precursor should give a radical pair that is a multiplet polarized by the RPM, with low field lines in emission (E) and high field lines in enhanced absorption (A).

A good example from the literature of a similar radical pair is that from the triplet state of benzophenone in n-hexadecane solution (Scheme 2, top), which we have used as a test system throughout the work described here. The solvent $n$-hexadecane was selected because it is an excellent $H$-atom donor and should give only two alkyl radicals (Scheme 2, right) that are quite distinct in their hyperfine splitting patterns. This is because one radical has an odd number of coupled protons and the other has an even number of coupled protons. Any triplet carbenes produced in $n$-hexadecane, by direct photolysis of the diazo compounds in Scheme 1, should lead to the same alkyl radicals, allowing for easy identification (Scheme 2, bottom). Furthermore, the relative intensities of the CIDEP signals for different diazo precursors, for solutions of similar absorbance, should track with the quantum yields for carbene production. Since we perform our TREPR experiments using

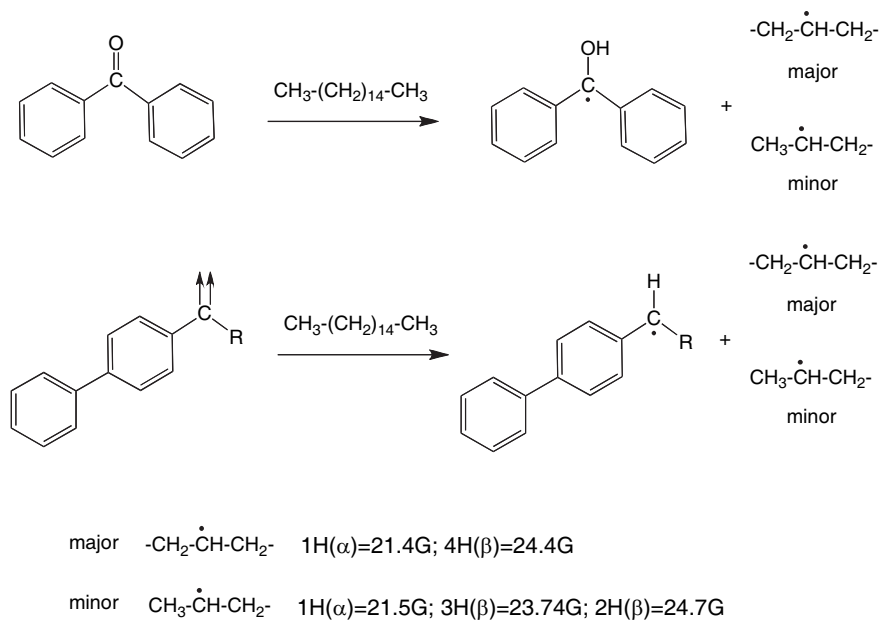

Scheme 2

direct excitation of the diazo compounds, i.e., without sensitization, we can assume that the initial excited state of the diazo compound has singlet multiplicity. Previous transient absorption work confirms that loss of nitrogen occurs from this state, and that intersystem crossing to the triplet takes place in the carbene molecular framework [10c-e, 12, 13].

Figure 1 shows the X-band TREPR spectrum acquired $200 \mathrm{~ns}$ after $308 \mathrm{~nm}$ laser flash photolysis of a solution of benzophenone $(0.1 \mathrm{M})$ in $n$-hexadecane at room temperature, along with a computer simulation using the literature param-

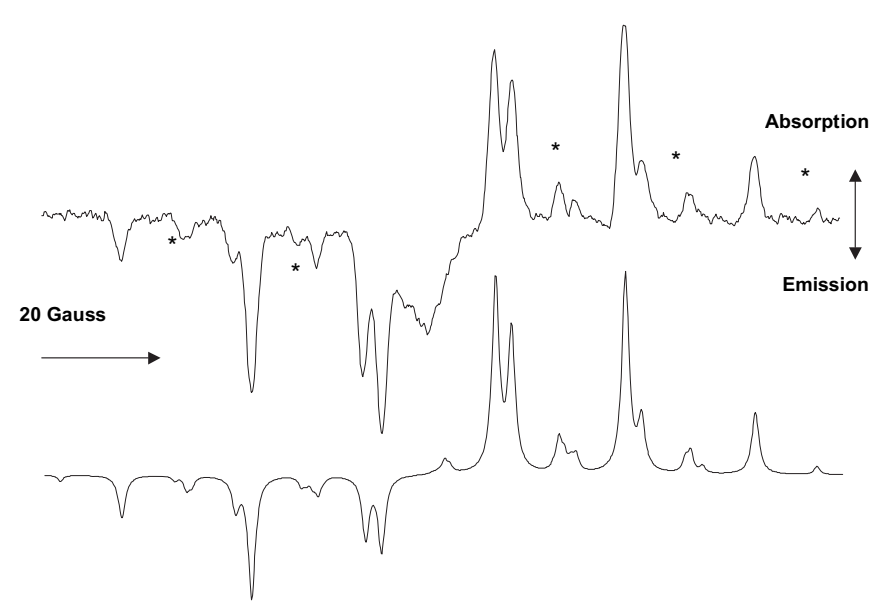

Fig. 1. Top: X-band TREPR spectrum acquired $200 \mathrm{~ns}$ after 308 $\mathrm{nm}$ laser flash photolysis of a solution of benzophenone $(0.1 \mathrm{M})$ in $n$-hexadecane at room temperature. In this and all subsequent spectra, transitions below the baseline are in emission, and those above the baseline show enhanced absorption intensity due to the Radical Pair Mechanism of CIDEP. Bottom: Simulation of the experimental spectrum using parameters for the two radicals shown in Scheme 2. Hyperfine coupling constants are also listed in Scheme 2 for each radical. The $g$-factor used was 2.0026 for both radicals. The broad emissive bump in the center of the experimental spectrum is due to the benzophenone ketyl radical, which is not simulated. Transitions marked with an asterisk are assigned to the minor secondary radical center at the penultimate carbon atom of $n$-hexadecane (Scheme 2). 
eters for the two secondary alkyl radicals shown in Scheme 2 . There are 8 structurally unique abstraction sites on the hexadecane molecule, a primary site on the methyl terminus, a secondary site on the penultimate carbon atom that has six coupled protons, and six other sites that have only five coupled protons. All 8 of these sites are doubly degenerate by symmetry, which has no effect on the appearance of the TREPR spectrum, but increases the intensity of the observed signals due to a higher ratio of $\mathrm{CH}_{2}$ to $\mathrm{CH}_{3}$ groups available for the $\mathrm{H}$-atom abstraction reaction. Reaction at the methyl terminus is too slow to be observed on time scale of our experiment, and the 6 sites with five coupled protons are indistinguishable within the resolution of our apparatus. Therefore, the spectrum in Figure 1 consists of transitions from only two hyperfine splitting patterns, which we designate as minor (6 coupling constants, radical centered on the penultimate secondary carbon) and major ( 5 coupling constants, radical centered on any other secondary carbon). The benzophenone ketyl radical appears as a broad emissive bump in the center of the spectrum in Figure 1 and is not included in the computer simulation.

Figure 2A shows the X-band TREPR spectrum obtained $200 \mathrm{~ns}$ after $308 \mathrm{~nm}$ laser flash photolysis of a solution of $\mathrm{BpCN}_{2} \mathrm{CF}_{3}$ (10 mM in $n$-hexadecane) at room temperature. Clearly there is $\mathrm{H}$-atom abstraction taking place (see more discussion below about this), and the CIDEP pattern is multiplet $\mathrm{E} / \mathrm{A}$, indicating that there is a triplet precursor to this radical pair. There is net A polarization also in this spectrum, and this could arise from a g-factor difference with the counter radical, which is a fluorinated benzylic-type radical from the biphenyl carbene structure (Scheme 2, bottom). Although the trifluoromethylbenzyl radical EPR spectrum is not known, most fluoroalkyl radicals have slightly higher g-factors than

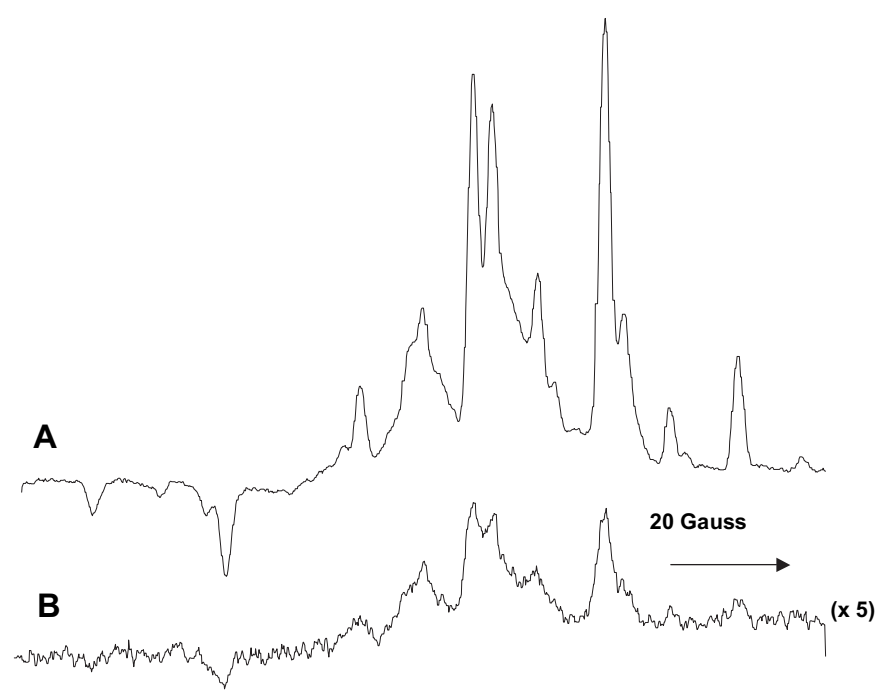

Fig. 2. A) X-band TREPR spectrum acquired $200 \mathrm{~ns}$ after $308 \mathrm{~nm}$ laser flash photolysis of a solution of $\mathrm{BpCN}_{2} \mathrm{CF}_{3}$ in $n$-hexadecane at room temperature. This spectrum was the first scan acquired. B) spectrum of the same system as A), except this is the third scan. Note the different scale for this spectrum compared to A). The fourth scan of this sample revealed very little signal intensity. their alkyl counterparts [19], which would place them at lower magnetic fields, and this is consistent with the observation of net RPM polarization here. The TREPR spectrum in Figure 2A was rapidly depleted. Figure 2B shows the same experiment after 3 scans of 2 minutes in length. Note the different scales for the two spectra. After only a few minutes photolysis the sample had bleached considerably into a colorless or slightly yellow color (from bright orange), indicating a high quantum yield reaction, which is also consistent with the transient optical data. Additionally, after 3 scans a white precipitate began to form in the solution, which is most likely the recombination product of the two radicals. This is a common observation in photoreduction reactions.

Alkyl radicals from the hexadecane solvent are clearly observed in Figure 2. To show that they are indeed the same radicals as the test system, they are plotted top and bottom in Figure 3. The line positions due to both types of alkyl radical line up perfectly. It is interesting to note that the CIDEP intensity is much higher in the top spectrum from the carbene than for benzophenone. This could be another reflection of the higher quantum yield for carbene (and hence radical) production, although it is also true that the absorbance of the diazo compound is higher at $308 \mathrm{~nm}$ than for benzophenone. Both factors would lead to a higher concentration of radicals in the solution. The slight difference in the intensity of the E/A multiplet CIDEP from the RPM in each spectrum is probably due to the g-factor difference between the two ketyl radicals.

It could be postulated that we are observing F-pairs from what would originally be a singlet radical pair from the singlet carbene. The F-pairs would exhibit E/A CIDEP patterns, whereas singlet born pairs would show $\mathrm{A} / \mathrm{E}$ polarization. The transfer of $\mathrm{A} / \mathrm{E}$ to $\mathrm{E} / \mathrm{A}$ polarization has been observed in some

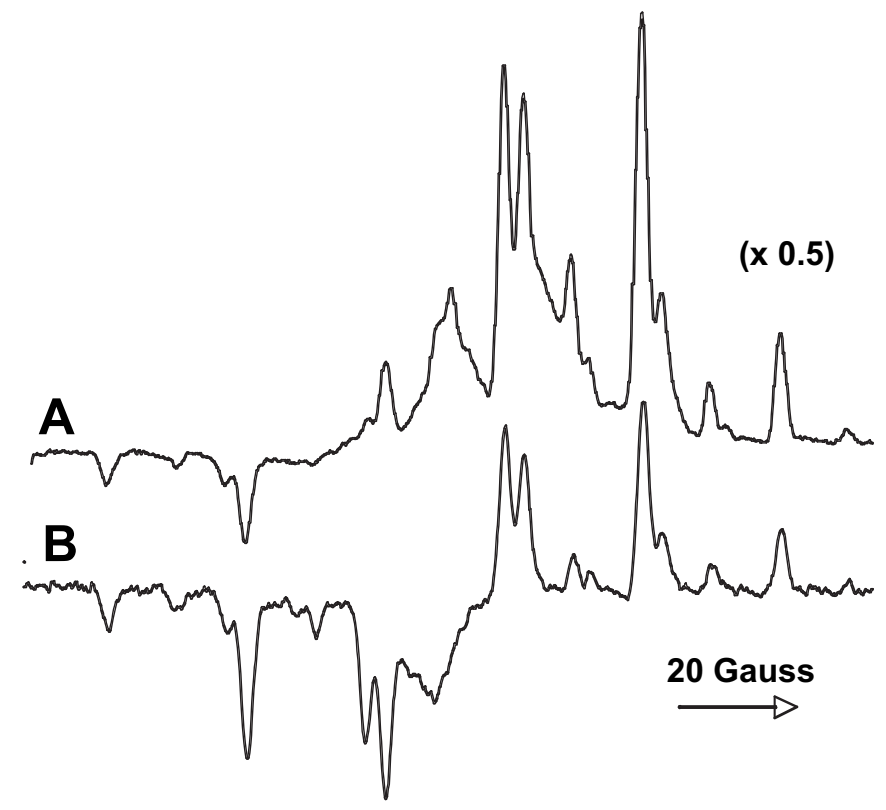

Fig. 3. A) X-band TREPR spectrum acquired $200 \mathrm{~ns}$ after $308 \mathrm{~nm}$ laser flash photolysis of a solution of $\mathrm{BpCN}_{2} \mathrm{CF}_{3}$ in $n$-hexadecane at room temperature. B) Test system spectrum from Figure 1 for comparison. 
systems. However, singlet-born radical pairs generally have shorter lifetimes and weaker polarizations than we are observing here. Also, hexadecane is a reasonably viscous solvent: Fpair formation is not favored on the time scale of our observation (200-500 ns after the laser flash), because diffusive pairs (F-pairs) would form too slowly.

Figure 4A shows the X-band TREPR spectrum acquired $200 \mathrm{~ns}$ after $308 \mathrm{~nm}$ laser flash photolysis of a solution of $\mathrm{BpCN}_{2} \mathrm{CO}_{2} \mathrm{CH}_{3}$ (17 mM in n-hexadecane) at room temperature. Alkyl radicals from a triplet precursor are also observed here. It is noteworthy that the signal-to-noise ratio is lower in these spectra compared to Figures 2 and 3, although the concentration of initial diazo compound was higher. This reflects a lower quantum yield for carbene (radical) production in this system, again very consistent with the transient optical data. Also, for this diazo compound the sample lifetime is much longer. Figure $4 \mathrm{~B}$ is the fifth 2-minute scan during this experiment and the intensity is almost the same as the first scan (Figure 4A). It should be noted, however, that the spectrum in Figure 4B was obtained at a longer delay time (400 ns) where the line widths are sharper therefore the transitions appear to be slightly more intense. This is a minor perturbation of the signal shape and we conclude that the long sample lifetime also supports a lower quantum yield process. Also, no white precipitate was observed with this sample, which is also qualitatively consistent with a lower quantum yield for carbene formation in $\mathrm{BpCN}_{2} \mathrm{CO}_{2} \mathrm{CH}_{3}$ vs $\mathrm{BpCN}_{2} \mathrm{CF}_{3}$.

Recalling Scheme $1 \mathrm{C}$ and the earlier transient optical absorption data, the $\mathrm{BpCN}_{2} \mathrm{COCH}_{3}$ diazo compound is expected to primarily undergo the Wolff rearrangement from the ground state singlet of the carbene structure, which would not lead to CIDEP because no radical pairs are formed in this process. Figure 5 shows TREPR results for this compound $(6 \mathrm{mM}$ in n-hexadecane). The system was flushed with $n$-hexadecane

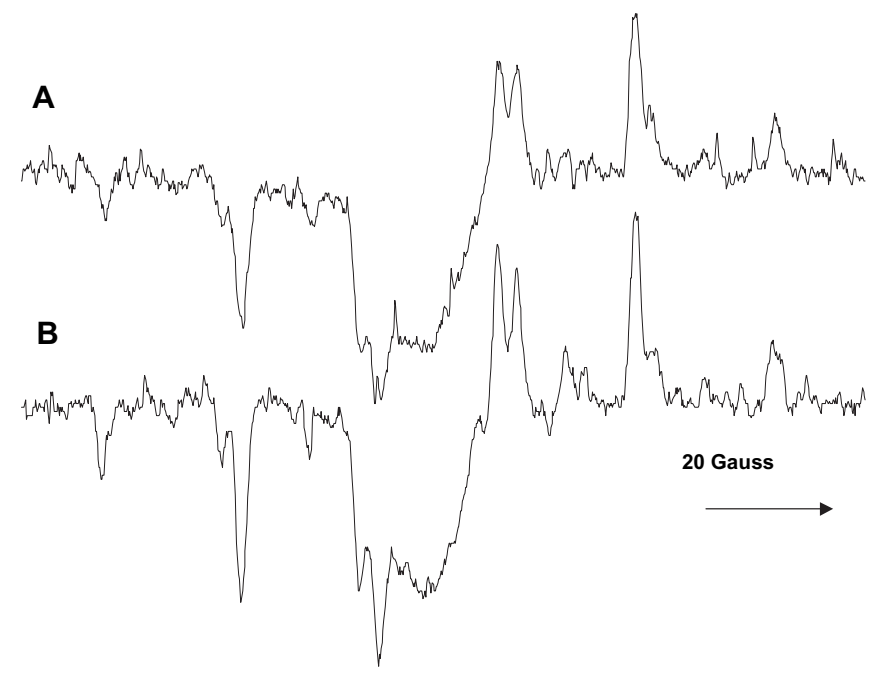

Fig. 4. A) X-band TREPR spectrum acquired $200 \mathrm{~ns}$ after $308 \mathrm{~nm}$ laser flash photolysis of a solution of $\mathrm{BpCN}_{2} \mathrm{CO}_{2} \mathrm{CH}_{3}$ in $n$-hexadecane at room temperature. B) Same spectrum after 5 scans, taken at a slightly later delay time (300 ns). and a solvent blank was run, shown in Figure 5B. The signals are identical and essentially flat, leading us to conclude that there are no radicals created in this photochemistry.

After obtaining a null result or flat line spectrum, it is worth confirming that the experiment is functional and this was done by running the benzophenone test system immediately after these runs, the results of which is shown in Figure $5 \mathrm{C}$. The spectrometer clearly detects the test system with similar signal to noise as obtained earlier (Figure 1A). All of the results in Figure 5 point to a singlet state process that is reasonably efficient and does not lead to detectable levels of CIDEP polarized free radicals. This is again remarkably consistent with the earlier optical work.

Finally, we report that for all three diazo compounds, the TREPR experiment was run in acetonitrile, where ground state singlet carbene formation is expected. No TREPR signals were detected in all three runs. It should be noted that the direct insertion of a singlet carbene into a $\mathrm{C}-\mathrm{H}$ single bond is a concerted process that does not involve free radical intermediates, therefore CIDEP is not expected. To test this hypothesis further, a small amount of 2-propanol was added to these solutions to see if the singlet carbene would undergo $\mathrm{H}$-atom abstraction in competition with $\mathrm{C}-\mathrm{H}$ bond insertion, but again no CIDEP was generated.

\section{Conclusions}

We have examined the solution photochemistry of three diazo compounds that lead to carbenes with different substitution patterns and reactivity, using TREPR spectroscopy at X-band. For two of the three diazo compounds studied, triplet-born free radicals are observed from $\mathrm{H}$-atom abstraction reactions, and they are unambiguously identified by spectral simulation.

\section{A}
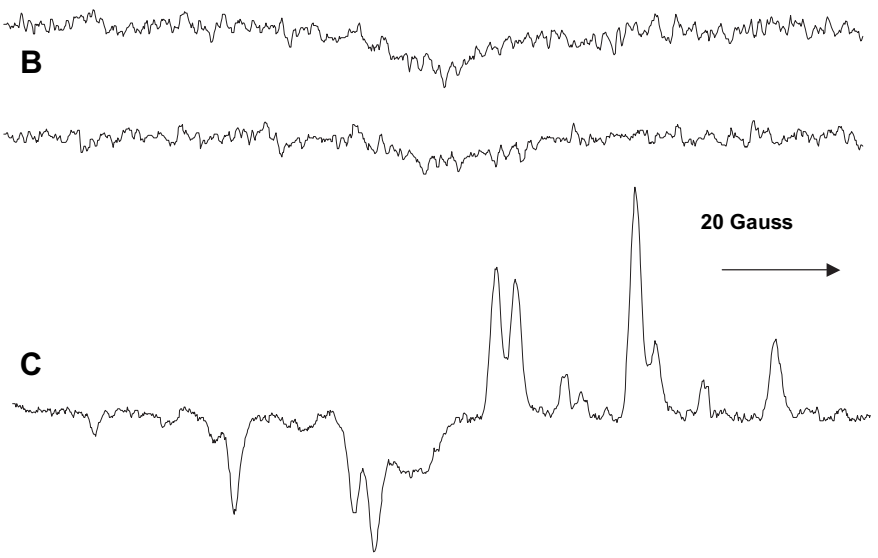

Fig. 5. A) X-band TREPR spectrum acquired $200 \mathrm{~ns}$ after $308 \mathrm{~nm}$ laser flash photolysis of a solution of $\mathrm{BpCN}_{2} \mathrm{COCH}_{3}$ in $n$-hexadecane at room temperature. B) Blank TREPR spectrum of $n$-hexadecane. C) Repeat of test system from Figure 1, acquired immediately after flushing with fresh solvent. 
The phase of the observed CIDEP patterns provide immediate confirmation of the spin state of the precursor, i.e., for BpCN $\mathrm{CO}_{2} \mathrm{CH}_{3}$ and $\mathrm{BpCN}_{2} \mathrm{CF}_{3}$, the carbene produced by direct photolysis is a ground state triplet. The intensity of the TREPR signals and the sample lifetimes over the course of the experiment can used to qualitatively estimate the relative quantum yields for carbene formation. The absence of any TREPR signal from the $\mathrm{BpCN}_{2} \mathrm{COCH}_{3}$ diazo compound is support for a singlet ground state of the carbene. This work highlights the utility of TREPR measurements on reactive intermediates in solution carbene chemistry with regard to photophysics and mechanism.

\section{Experimental}

Synthesis. The syntheses of the diazo precursors were either by pyrolysis of the tosylhydrazone salt or by reacting tosyl azide with acidic methylene alpha-hydrogens of biphenylyl carbonyl compounds under basic conditions. The detailed procedures were reported previously $[12,13]$.

TREPR Spectroscopy. Our TREPR apparatus has been described previously in several recent publications [20,21]. Briefly, the $308 \mathrm{~nm}$ laser is fired at a repetition rate of $60 \mathrm{~Hz}$, while sampling the direct detection EPR signal from the microwave bridge ( $\mathrm{CW}$ mode) using a gated boxcar signal averager. The external magnetic field is swept over 2 or 4 minutes with 100 or 300 ns gates sampling the EPR signal 5-10 times at each magnetic field point. The flow system was flushed and a solvent blank was run in between all experiments. All spectra have center field of $3375 \mathrm{G}$, sweep width of $150 \mathrm{G}$, microwave frequency $9.47 \mathrm{GHz}$, microwave power $10 \mathrm{~mW}$. Samples were flowed through the microwave resonator using a micropump from a reservoir that was constantly purged with nitrogen gas bubbles (for 10 minutes prior to and during EPR experiments).

\section{References}

1. Reactive Intermediate Chemistry, Moss, R. A., Platz, M. S., Jones, M., Jr., Eds., Wiley-Interscience, Hoboken, N.J., 2004, Chapters 7-9.

2. (a) Closs, G. L. In Carbenes Vol. II; Moss, R. A., Jones, M. J., Jr., Eds.; Wiley: New York, 1975; p 159. (b) Trozzolo, A. M.; Wasserman, E. In Carbenes Vol. II; Moss, R. A., Jones, M. J., Jr., Eds.; Wiley, New York, 1973; p 185. (c) Kirmse, W. Carbene Chemistry; Academic Press: New York, 1964. (d) Carbenes Vol. I; Moss, R. A., Jones, M. J., Jr., Eds.; Wiley: New York, 1973.

3. (a) Kinetics and Spectroscopy of Carbenes and Biradicals, Platz, M. S., Ed., Plenum (New York), 1990. (b) Bally, T. In Reactive Intermediate Chemistry; Moss, R.A., Platz, M.S., Jones, M. Jr., Eds; John Wiley \& Sons, Hoboken, N.J., 2004, p797-845.
4. (a) Jones, M. Jr., Moss, R.A., In Reactive Intermediate Chemistry; Moss, R.A., Platz, M.S., Jones, M. Jr., Eds; John Wiley \& Sons, Hoboken, N.J., 2004, p273-328. (b) Tomioka, H., In Reactive Intermediate Chemistry; Moss, R.A., Platz, M.S., Jones, M. Jr., Eds; John Wiley \& Sons, Hoboken, N.J., 2004, p375-461. (c) Wang J., Burdzinski, G., Gustafson T. L., Platz, M. S. J. Org. Chem., 2006, 71, 6221-6228. (d) Wang J., Burdzinski, G., Gustafson T. L., Platz, M. S. J. Am. Chem. Soc., 2007, 129, 25972606.

5. (a) Roth, H. D. J. Am. Chem. Soc. 1971, 93, 4935-4936. (b) Roth, H. D., In Reactive Intermediate Chemistry; Moss, R.A., Platz, M.S., Jones, M. Jr., Eds; John Wiley \& Sons, Hoboken, N.J., 2004, pp 205-272.

6. Shavitt, I. Tetrahedron 1985, 41, 1531.

7. Engelking, P. C.; Corderman, R. R.; Wendoloski, J. J.; Ellison G. B.; ONeil, S. V.; Lineberger, W. C. J. Chem. Phys. 1981, 74, 5460.

8. (a) Arenas, J. F.; Lopez-Tocon, I.; Otero, J. C.; Soto, J. J. Am. Chem. Soc. 2002, 124, 1728. (b) Yamamoto, N.; Bernardi, F.; Bottoni, A.; Olivucci, M.; Robb, M. A.; Wilsey, S. J. Am. Chem. Soc. 1994, 116, 2064. (c) Bernardi, F.; Olivucci, M.; Robb, M. A.; Vreven, T.; Soto, J. J. Org. Chem. 2000, 65, 7847. (d) Bigot, B.; Ponec, R.; Sevin, A.; Devaquet, A. J. Am. Chem. Soc. 1978, 100, 6575.

9. (a) Langan, J. G.; Sitzmann, E. V.; Eisenthal, K. B. Chem. Phys. Lett. 1984, 110, 521-527. (b) Langan, J. G.; Sitzmann, E. V.; Eisenthal, K. B. Chem. Phys. Lett. 1986, 124, 59-62. (d) Sitzmann, E. V.; Langan, J. G.; Griller, D.; Eisenthal, K. B. Chem. Phys. Lett. 1989, 161, 353-360. (d) Sitzmann, E. V.; Langan, J.; Eisenthal, K. B. J. Am. Chem. Soc. 1984, 106, 1868-1869.

10. (a) Geise, C. M.; Wang, Y.; Mykhaylova, O.; Frink, B. T.; Toscano, J. P.; Hadad, C. M. J. Org. Chem. 2002, 67, 3079-3088. (b) Wang, Y.; Hadad, C. M.; Toscano, J. P. J. Am. Chem. Soc. 2002, 124, 1761-1767. (c) Wang, J.; Burdzinski, G.; Gustafson, T. L.; Platz, M. S. J. Org. Chem.2006, 71, 6221-6228. (d) Wang, J.; Burdzinski, G.; Gustafson, T. L.; Platz, M. S. J. Am. Chem. Soc. 2007, 129, 2597-2606. (e) Wang, J.; Kubicki, J.; Hilinski, E. F.; Mecklenburg, S. L.; Gustafson, T. L.; Platz, M. S. J. Am. Chem. Soc. 2007, 129, 13683-13690.

11. Wang, J.; Kubicki, J.; Peng, H.; Platz, M. S. J. Am. Chem. Soc. 2008, 130, 6604 .

12. Wang, J.; Kubicki, J.; Gustafson, T. L.; Platz, M. S. J. Am. Chem. Soc. 2008, 130, 2304.

13. Wang, J.; Burdzinski, G.; Kubicki, J.; Platz, M. S. J. Am. Chem. Soc. 2008, 130, 11195-11209.

14. Wang, J.; Sheridan, R. S. Org. Lett., 2007, 9, 3177.

15. Burdzinski, G.; Wang, J.; Gustafson, T. L.; Platz, M. S. J. Am. Chem. Soc. 2008, 130, 3746-3747.

16. Closs, G.L; Closs, L. E. J. Am. Chem. Soc. 1969, 91, 4549.

17. Roth, H. D. Acc. Chem. Res. 1977, 10, 85.

18. Harbron, E. J.; Forbes, M. D. E. Encyclopedia of Chem. Phys. Phys. Chem. 2001, 2, 1389.

19. Chen, K. S.; Krusic, P. J.; Meakin, P.; Kochi, J. K. J. Phys. Chem. 1974 78, 2014-2030.

20. Forbes, M. D. E. Photochem. Photobiol. 1997, 65, 73.

21. Carbon-Centered Radicals and Radical Cations, Forbes, M. D. E., Ed., Wiley (New York), 2009, (in press), Chapter 14. 